\title{
IMPLEMENTASI PERATURAN WALIKOTA NOMOR 9 TAHUN 2009 DALAM REVITALISASI PASAR TRADISIONAL DI KOTA DENPASAR
}

\author{
I Putu Deny Adistanaya Putra, Ni Luh Made Mahendrawati, Luh Putu Suryani \\ Fakultas Hukum Universitas Warmadewa, Denpasar-Bali, Indonesia \\ iproufoyoutomorrow4@gmail.com, made.mahendrawati@gmail.com, putusuryani099@gmail.com
}

\begin{abstract}
Abstrak
Revitalisasi pasar tradisional sangat penting dilakukan, karena selama ini diketahui telah Ada persaingan tidak sehat antara pasar tradisional dan pasar modernnpenelitian ini bertujuan mengkaji Faktor apakah yang mempengaruhi pelaksanaan Revitalisasi Pasar Tradisional di Kota Denpasar dan menelaah pelaksanaan Revitalisasi Pasar Tradisional di Kota Denpasar. Penelitian ini menggunakan tipe penelitian hukum empiris dengan pendekatan perundang-undangan. Sumber data yang digunakan adalah sumber data primer dan sumber data sekunde. Teknik pengumpulan data dalam penelitian ini dilakukan melalui wawancara. Implementasi regulasi ini telah berhasil dilaksanakan, salah satunya di pasar Badung kota Denpasar. Hasil penelitian menunjukkan bahwa faktor yang mempengaruhi implementasi peraturan Perundang-undangan revitalisasi pasar Pemerintah Kota Denpasar, yaitu: komunikasi, sumber daya, struktur birokrasi, karakter, lingkungan ekonomi, sosial dan politik, serta respon masyarakat, dapat menjadi kendala dalam proses pelaksanaan revitalisasi pasar Kreneng. Dalam pelaksanaan program revitalisasi pasar tradisional di kota Denpasar meliputi sumber daya manusia dan pendanaan atau anggaran. Sumber daya manusia merupakan salah satu faktor yang menentukan keberhasilan suatu kebijakan atau rencana.
\end{abstract}

Kata kunci : Pasar Tradisional, Kebijakan Pasar, Revitalisasi

\begin{abstract}
It is important to implement traditional market revitalization, As we all know, there is unfair competition between the traditional market and the modern market. This research has two problem formulations, namely: 1) What factors influence the implementation of Revitalization of Traditional Markets in Denpasar City? 2) How is the implementation of Revitalization of Traditional Markets in Denpasar City? This research uses empirical legal research type. The data collection technique in this research is done through interviews. The implementation of this regulation has been successfully implemented, one of which is in the Badung market, Denpasar city. The purpose of this study is to identify, analyze and describe a model of cooperation between participants in the revitalization of traditional markets in the Kreneng market, Denpasar city from the perspective of good governance. Factors that influence the implementation of market revitalization legislation for the Denpasar City Government, namely: communication, resources, bureaucratic structure, character, economic, social and political environment, as well as public response, can become obstacles in the process of implementing the Kreneng market revitalization. The implementation of the traditional market revitalization program in the city of Denpasar includes human resources and funding / budget. Human resources are one of the factors that determine the success of a policy / plan.
\end{abstract}

Keywords: Revitalisation, Traditional Markets, Revitalizatio./

\section{PENDAHULUAN}

Sejarah mencatat bahwa pasar tradisional diperkirakan sudah ada sejak berdirinya Kerajaan Kutai Kartanegara pada abad ke-5 Masehi, pertama-tama adalah sistem pertukaran kebutuhan sehari-hari dengan pelaut asal Tiongkok. Pedagang saat itu menyebarkan barangnya di atas tikar, dan disinilah barang tersebut ditukar. Pasar pada masa itu tidak hanya menjadi ruang komunikasi bagi pembeli dan penjual, tetapi juga tempat bertemunya masyarakat dan bangsawan, bahkan pasar sering dijadikan sebagai bagian dari strategi politik untuk bertukar informasi penting pada waktu itu (N. Ariani, 2009)

Keberadaan pasar tradisional merupakan warisan genetik para pendahulu penggiat ekonomi Indonesia yang saat ini sedang mengalami kemunduran dan kelemahan. Selain itu, untuk membangun pedagang masih sulit bagi pedagang untuk menyesuaikan diri dan mengatur sendiri, semakin banyaknya pedagang akan mengurangi ruang gerak pengunjung dan mengakibatkan 
terabaikannya penataan ruang, pedagang dan pengunjung pasar kurang memiliki kesadaran akan disiplin, rapi dan tertib, pengelolaan parker yang tidak teratur namun hal yang terpenting adalah perilaku konsumen dimana keadaan permintaan yang berubah terjadi dengan cepat, tetapi karena informasi dan kemampuan yang terbatas, dan kurangnya persiapan untuk persaingan, pedagang pasar tidak dapat mengikutinya.

Ketika pasar sudah mencapai puncak kejayaannya, satu pihak politik merasa dirugikan. Pihak itu adalah Pelaku usaha dari pasar tradisional. Ketika pasar modern mendominasi dan pasar tradisional tidak mampu bersaing maka akan timbul beberapa ancaman yaitu (1) karena letak supermarket kecil, supermarket dan supermarket besar yang strategis, pembeli cenderung ke pasar modern sehingga memudahkan konsumen. (2) Karena bangkrutnya pasar traidional, potensi pendapatan daerah yang diperoleh dari UMKM berkurang, sedangkan pasar modern tidak banyak memberikan kontribusi bagi pendapatan daerah karena hanya mengandalkan pajak pada baliho dan Izin Mendirikan Bangunan (IMB). (3) Perbandingan jam kerja, dimana pasar modern beroperasi 13 jam sehari (Bintoro, 2012).

Ada beberapa penelitian terdahulu yang relevan dengan penelitian ini yaitu Ariani \& Subawa, (2017) Revitalisasi pasar merupakan tanggungjawab pemerintah, revitalisasi ini samgan sulit diterapkan karena kehadiran pasar modern, kemampuan marketing pedagang, masyarakat yang heterogen dan peran rentenir masih ada dalam permodalan pedagang, hal inilah yang menjadi hambatan bagi terlaksananya revitalisasi pasar tradisional. Toko Modern sangat menguntungkan karena banyak diminati konsumen sehingga menimbulkan persaingan yang luar biasa, hal ini akan menjadi ancaman serius bagi bagi toko yang bermodal kecil dan sistem pasarnya masih tradisional (Kadek et al., 2021) \& (Widyanto \& Laksana, 2020). Berdasrakan uraian di atas maka penelitian ini bertujuan untuk mengkaji Faktor apakah yang mempengaruhi pelaksanaan Revitalisasi Pasar Tradisional di Kota Denpasar dan menelaah pelaksanaan Revitalisasi Pasar Tradisional di Kota Denpasar

\section{METODE PENELITIAN}

Tipe penelitian yang digunakan adalah penelitian hukum empiris. Hukum empiris adalah metode penelitian hukum yang fungsinya untuk melihat hukum dalam praktek dan mempelajari cara kerja hukum dalam masyarakat. Karena penelitian hukum yang dilakukan didasari pada fakta yang ada di masyarakat, bertujuan untuk memahami pelaksanaannya, kendala dan cara mengatasinya (Usman \& Husaini, 2006). Dalam penelitian ini dipergunakan pendekatan sosiologis. Sumber data yang digunakan adalah sumber data primer dan sumber data sekunder. Sumber data primer yaitu penelitian yang diperoleh dari sumber penelitian yang aslinya yang berupa wawancara, pendapat dari pihak Perumda Pasar kota Denpasar atas permasalahan implementasi . Sumber data sekunder yaitu sumber data yang secara tidak langsung memberikan data kepada penelti seperti data dari bahan kepustakaan (library search). Lokasi penelitian ini dilakukan secara langsung pada Perumda Pasar kota Denpasar yang ada di daerah kota Denpasar yang beralamat di Jalan Hasanuddin No.1 Pertokoan Suci Sarijaya Lantai III. Untuk memperoleh data yang relevan dipergunakan teknik wawancara dan studi kepustakaan. Analisis data yang dipergunakan adalah kualitatif dimana peneliti melakukan analisis dengan cara atau langkah-langkah yang dilakukan oleh Direktur Perumda Pasar kota Denpasar dalam melaksanakan implementasi Peraturan Walikota Nomor 9 Tahun 2009 dalam Revitalisasi Pasar Tradisional di Kota Denpasar (Sugiyono, 2005).

\section{HASIL DAN PEMBAHASAN}

\section{Faktor yang Mempengaruhi Pelaksanaan Revitalisasi Pasar Tradisional di Kota Denpasar}

Sebagaimana diketahui, target pelaksanaan Revitalisasi di Kota Denpasar adalah Pasar tradisional. Namun kenyataannya, situasi aktual menunjukkan bahwa permasalahan infrastruktur sedang menjadi masalah yang cukup kritis di pasar tradisional, antara lain kebersihan, buruknya perawatan tempat pembuangan sampah, minimnya tempat parkir dan buruknya sirkulasi udara. Belum lagi maraknya Pedagang kaki lima yang otomatis merugikan pedagang yang berdagang di lingkungan pasar, dan harus membayar sewa dan retribusi secara penuh. Barang yang dijual oleh Pedagang kaki lima hampir sama dengan semua barang yang dijual di pasar. Pedagang kaki lima hanya menjual daging segar. Oleh karena itu, sebagian besar pembeli tidak perlu masuk pasar untuk berbelanja karena bisa membeli dari pedagang luar pasar. Kondisi pasar tradisional umumnya memprihatinkan. Banyak 
pasar tradisional di kawasan ini yang tidak terawat, sehingga pasar modern menawarkan berbagai keunggulan dan kini terancam dengan keberadaan pasar modern. Artinya dalam hal revitalisasi pasar tradisional, tingkat implementasi Peraturan Walikota Nomor 9 Tahun 2009 lebih rendah dari target yang ditetapkan.

Konsep kondisi atau gejala ini disebut dengan implementasi gap, dalam hal ini dalam proses implementasi selalu terdapat perbedaan antara hasil yang sebenarnya dicapai karena implementasi atau realisasi dari kemungkinan kebijakan tertentu (Wahab, 1997). Implementasi Peraturan revitalisasi Pasar Tradisional Dalam proses pelaksanaannya tidak terlepas dari berbagai kendala yang dihadapi masyarakat dan pihak terkait yaitu Secara Eksternal yaitu pertumbuhan pasar modern di Banjar Kreneng dan keberadaan toko online menjadi tantangan untuk terus memperbaiki dan Secara internal yakni perilaku pedagang, heterogenitas tipe masyarakat dan peran lintah darat dalam modal pedagang.

Melihat adanya faktor-faktor di atas, maka perlu dilakukan langkah-langkah strategis bagi birokrasi dan pengambil kebijakan di daerah untuk mengatasi masalah tersebut. Salah satu langkah yang dapat dilakukan adalah merumuskan kembali kebijakan dengan merumuskannya, dengan tujuan agar pelaksanaan kebijakan atau rencana tersebut lebih tepat sasaran. Dalam pembenahan kebijakan melalui tatanan, pembudidayaan dan pengelolaan pasar tradisional, serta perlindungan pasar modern yang ada di pasar tradisional, faktor dasar yang menjadi penyebab ancaman terhadap pasar tradisional juga harus terancam (Mahathir \& Iqbal, 2017). Hal ini dikarenakan organisasi pasar, birokrasi / pemerintahan dan model sosial yang digambarkan dalam konteks hubungan segitiga akan membuat satu unsur saling bergantung dengan komponen lainnya dan membentuk jaringan kebijakan, dan peran satu sama lain tidak dapat diabaikan. Berhasil menerapkan kebijakan.

\section{Pelaksanaan Revitalisasi Pasar Tradisional di Kota Denpasar}

Pengembangan ekonomi daerah adalah proses kegiatan yang dilakukan oleh pemerintah daerah dan masyarakatnya dalam mengelola semua sumber daya yang tersedia untuk kesejahteraan dan kesejahteraan rakyatnya (Tumangkeng, 2018). Dalam penyelenggaraan otonomi daerah diperlukan arah yang benar dan mengerahkan segala potensi yang dimiliki untuk menjawab tantangan era globalisasi. Diperlukan upaya pelaksanaan pemberdayaan daerah untuk mendorong pemanfaatan yang terbatas dan upaya pembangunan untuk meningkatkan fleksibilitas dan daya saing perekonomian daerah dengan meningkatkan kemampuan pemerintah daerah dan masyarakat untuk secara efektif meningkatkan perekonomian daerah, meningkatkan kesempatan kerja dan pendapatan masyarakat, dan sebaliknya Kapasitas ekonomi dan pendapatan daerah.

Revitalisasi tersebut dilaksanakan bersama oleh Kementerian Perindustrian dan Perdagangan, UPT, pejabat pasar dan pelaku ekonomi untuk melaksanakan berbagai strategi ekonomi yang telah dirumuskan, termasuk kegiatan zonasi dan strategi untuk mendorong pertumbuhan kegiatan ekonomi di pasar itu sendiri. Kegiatan zonasi dirancang untuk mengubah kondisi pasar agar pasar lebih tertib dan memberikan kenyamanan bagi pelaku ekonomi. Upaya zonasi yang dilakukan oleh Kementerian Perindustrian dan Perdagangan dilakukan menurut regulasi yang berlaku sesuai dengan standar nasional Indonesia (Mahendrawati N. , 2020).

Pemerintah daerah kota Denpasar sudah berbagai upaya telah dilakukan untuk mengembangkan perekonomian masyarakat, salah satunya dengan pelaksanaan rencana revitalisasi pasar tradisional. Namun berdasarkan berbagai kenyataan yang ada, revitalisasi pasar yang dilaksanakan di Kota Denpasar bukanlah pilihan terbaik. Pada dasarnya upaya pembenahan pasar tradisional tidak hanya difokuskan pada unsur fisik, tetapi yang lebih penting adalah pembenahan manajemen merupakan suatu keharusan. Pengelolaan pasar yang sempurna akan membuat pasar tradisional semakin terkonsentrasi, dalam hal ini juga terkait dengan keberadaan penyedia jasa pasar, prosedur dan prosedur operasi standar. Oleh karena itu, perbaikan faktor non material juga menjadi faktor penting untuk pengembangan pasar yang berkelanjutan. Revitalisasi merupakan peluang terbaik, dan harus dimanfaatkan sebaik-baiknya oleh pemerintah daerah sekaligus memperbaiki kondisi pasar tradisional. Profesionalisme manajer pemasaran adalah suatu faktor yang mempengaruhi pelaksanaan rencana revitalisasi agar tujuan yang diharapkan tercapai. Tidak dapat dipungkiri bahwa pembenahan yang dilakukan menjadi salah satu penyebab perkembangan ekonomi 
masyarakat di daerah ini, karena pada kenyataannya keberadaan pasar tradisional merupakan tulang punggung perekonomian rakyat. Dari data yang diperole diketahui, Denpasar memiliki 16 pasar yang dikelola oleh PD Pasar dan 37 pasar yang dikelola oleh desa Pakraman yang diusahakan oleh Badan Pemberdayaan Masyarakat (BPM). Kepala Dinas Perdagangan, Perindustrian, dan Perdagangan Kota Denpasar, mengatakan sejak 2011, Pemerintah Kota Denpasar telah memulihkan pasar yang dikelola PD Pasar dan pasar milik Desa Pakraman

Pelaksanaan Rencana Revitalisasi Pasar Tradisional Kota Denpasar meliputi sumber daya manusia dan anggaran. Sumber daya manusia merupakan salah satu aspek penentu keberhasilan program. Sumber daya manusia dan non sumber daya manusia. PD Pasar berhak memperbaiki sarana dan prasarana pasar, kemudian mengacu pada juknis Kementerian Perdagangan yang bertanggung jawab atas revitalisasi pasar yaitu Kepala Dinas Perdagangan dan Pembina Pasar (pengelola pasar). Kemudian selalu berkoordinasi dengan Perumda Pasar, dan rencana revitalisasi pasar sepenuhnya menjadi tanggung jawab Dinas Perindustrian, Perdagangan, Energi dan Sumber Daya Mineral. Terwujudnya perkembangan ini tidak hanya bertumpu pada perkembangan tubuh, tetapi juga mengubah mentalitas pedagang saat menjual komoditas yang bersih dan higienis, serta tidak melemahkan konsep pasar masyarakat, yaitu proses jual beli dan tawar menawar.

Berbagai upaya dilakukan pemerintah untuk merevitalisasi pasar tradisional di Kota Denpasar. Upaya tersebut terbagi dalam aspek fisik dan non fisik. Secara fisik artinya pembangunan dan pemeliharaan fasilitas pasar, termasuk:

1. Pemilihan letak pasar agar tetap seperti apa adanya karena memenuhi kriteria yang terdapat dalam peraturan perundang-undangan dan pemilihan bahan bangunan yang berkualitas.

2. Perbaikan saluran air didukung dengan pemeriksaan rutin sebulan sekali.

3. Tempat pembuangan akhir yang disediakan lebih luas, dan desainnya mempermudah akses jalan bagi truk pengangkut sampah.

4. Menyediakan lahan parker dengan standar yang berlaku, yaitu terdapat pemisahan yang jelas dengan jenis kendaraan, area bongkar muat yang tersedia dipisahkan, serta tidak menganggu akses dan keluar pasar.

5. Meningkatkan total toilet/kamar mandi umum yang dipisahkan atas pria dan wanita.

Indikator permasalahan selanjutnya adalah kerjasama antara PD Pasar dan Walikota untuk menjadikan Pasar Tradisional basis yang modern, kerjasama ini terkendala oleh lambatnya penurunan anggaran dan penataan yang dilakukan harus menunggu keputusan dari pusat. Mengingat sistem pengelolaan Pasar Tradisional sudah terdesentralisasi dan menunggu koordinasi dari atas ke bawah, maka pengaturan tersebut tidak dapat dilakukan kecuali menghambat kerjasama antara walikota Pasal Pasal dan walikota. Salah satu indikatornya adalah keterkaitan antara Pasar dengan Pedagang. dengan

Perumda Pasar menghadapi kendala internal dan eksternal, antara lain relokasi pedagang dan kendala dalam bentuk transaksi, karena pedagang memiliki keinginan yang berbeda untuk memberikan relokasi sesuai dengan Peraturan Walikota Nomor 9 Tahun 2009. Pembatasan anggaran inilah yang terpenting di setiap aktivitas. Karena setiap kegiatan membutuhkan anggaran agar kegiatan tersebut dapat berjalan dengan lancar. Apalagi dalam pembangunan, yang terpenting adalah anggaran. Pasar Badung dan Pasar Kumbasari mendapat dana dari pasar yang dikelola oleh PD Pasar. Tentunya juga ada pelaksanaan rencana revitalisasi. Anggaran yang digunakan adalah untuk merencanakan anggaran dari marketsize untuk merevitalisasi pasar di kota Denpasar. Lain halnya karena kami Menurut permintaan pasar yang meningkat dan permintaan pasar berbeda. Tetapi dari perspektif PD Pasar terdapat penyelesaian masalah terhadap pembangunan pasar, yaitu menggunakan dana swadaya untuk membangun, kerjasama antara PD Pasar dengan pedagang Pasar Kreneng dapat dijelaskan sebagai berikut:

1. Untuk pedagang pasar kreneng akan dikenakan dana yang cukup mahal pada pembangunan tempat kios atau los yang dilakukan oleh pihak PD Pasar dan;

2. Ketika pedagang Pasar Kreneng Membangun los dan kios harus sesuai dengan ketentuan PD Pasar Kota Denpasar oleh PD Pasar Kota Denpasar, lalu pedagang Pasar Badung akan dikenakan biaya yang lebih murah.Melalui solusi ini, jika dana mandiri dapat dilaksanakan sesuai dengan rencana yang telah ditetapkan oleh PD Pasar maka kendala yang dihadapi dapat teratasi. Untuk melaksanakan rencana tersebut, pedagang PD Pasar dan Pasar Badung harus melakukan koordinasi di tempat dan secara transparan melakukan rencana swadaya dana untuk mencegah hal 
yang tidak diinginkan terjadi.

Saat ini, Denpasar tercatat ada 295 toko modern, tetapi jumlah tersebut tidak akan dikurangi, apalagi ditambah. Pemerintah akan memperketat izin usaha bagi yang masa berlaku izinnya telah habis. Dengan begitu jumlah toko modern akan berkurang dengan sendirinya. Menurut (Wiranata, 2020) bahwa Pada kota Denpasar sudah diberikan regulasi tentang jarak toko modern satu dengan yang lain tidak boleh berdekatan, jaraknya harus $1 \mathrm{~km}$, dan barang yang dijual di toko tidak boleh jenis barang yang dijual di pasar tradisional.

\section{SIMPULAN DAN SARAN}

\section{Simpulan}

Berdasarkan analisis data, dapat disimpulkan bahwa Fakror-faktor yang mempengaruhi revitalisasi pasar tradisional adalah Hambatan internal perilaku pedagang, keragaman tipe masyarakat dan peran pemberi pinjaman masih menjadi urat nadi modal pedagang. Hambatan eksternal pertumbuhan pasar modern dan toko online di kawasan Banjar Kreneng menjadi tantangan untuk terus meningkatkannya. Kesalahan antara pedagang dan kantor perdagangan, area corong menjadi alasan mengapa pedagang menolak pejabat perdagangan dan pemimpin pasar. Selanjutnya Pelaksanaan pada Revitalisasi Pasar tradisional di Kota Denpasar belum efektif dikarenakan PD Pasar mendapatkan kendala dari dalam maupun dari luar antara lainnya, relokasi terhadap pedagang dan sisi bentuk dagangan karena keinginan pedagang berbeda harus memberikan relokasi menurut peraturan walikota nomor 9 tahun 2009, Batasan anggaran merupakan aspek terpenting dari setiap kegiatan. Karena setiap kegiatan membutuhkan dan membutuhkan anggaran agar kegiatan tersebut dapat berjalan dengan lancar.

\section{Saran}

Berdasarkan simpulan penelitian di atas, adapu saran yaitu Kepada Pemerintah Kota Denpasar dan Perumda Pasar untuk lebih mengoptimalkan posisi pasar Kreneng yang ada, dan lebih sering berdiskusi dengan para pedagang di pasar Kreneng agar pasar dapat dimanfaatkan secara maksimal dan pedagang serta Pemerintah Kota Denpasar dapat merasakan adanya asas manfaat dengan adanya pengaturan pasar tradisional sesuai dengan pasal 2 Peraturan Walikota Nomor 9 Tahun 2009. Diharapkan juga kepada Pedagang harus lebih menyadari hak dan kewajibannya sebagai pedagang, terutama dalam membersihkan dan melaksanakan penataan struktur pasar untuk lebih bisa mentaati aturan yang telah dibuat oleh Pemerintah Kota Denpasar dan Perumda Pasar agar tercipta suasana pasar yang nyaman dan dapat berdaya saing.

\section{DAFTAR PUSTAKA}

Ariani, N. (2009). Penataan Pasar-pasar tradisional di Indonesia berdasarkan teori Von Stufennaufbau De Rechtsordnung. Yogyakarta. Universitas Janabadra.

Ariani, P., \& Subawa, N. S. (2017). Implementation of Revitalization Policy of Nyanggelan Market in Denpasar City Government. Jurnal Administator, 9(1), 13-27.

Bintoro, K. (2012). Implementasi Kebijakan Zonasi Pasar Tradisional dan Pasar Modern. Jurnal Dinamika, 12(45-59).

Kadek, N., Sri, D., Dewi, L., Luh, N., Mahendrawati, M., \& Dwi, G. (2021). Implementasi Peraturan Walikota Denpasar Nomor 9 Tahun 2009 Tentang Penataan dan Pembinaan Pasar Tradisional, Pusat Perbelanjaan dan Toko Modern. Jurnal Analogi Hukum, 3(1), 22-26.

Mahathir, \& Iqbal, M. (2017). Implementasi Kebijakan Tentang Penataan, Pembinaan, dan Pengelolaan Pasar Tradisional serta Toko Modern. Malang. Universitas Islam Raden Rahmat.

Sugiyono. (2005). MemahamiPenelitian Kualitatif. Bandung: Alfabeta.

Tumangkeng, S. (2018). Analisis Potensi Ekonomi di Sektor dan Sub Sektor Pertanian, Kehutanan dan Perikanan Kota Tomohon. Jurnal Berkala Ilmiah Efisiensi, 18(1), 127-138.

Usman, \& Husaini. (2006). Metode Penelitian Sosial. Jakarta. Bumi Aksara.

Wahab, A. (1997). Analisis Kebijaksanaan dan Formulasi ke Implementasi Kebijaksanaan Negara. Jakarta. Bumi Aksara. 
Widyanto, N. A., \& Laksana, I. G. N. D. (2020). Efektivitas Peraturan Wali Kota Denpasar Nomor 9Tahun 2009 tentang Penataan Pasar Tradisional Pusat Perbelanjaan dan Toko Modern. Jurnal Kertha Semaya, 8(4), 621-632. 